\title{
Suplementação dietética de fitase sobre o metabolismo de nutrientes de frangos de corte
}

\section{Guilherme Rodrigues Lelis ${ }^{1}$, Luiz Fernando Teixeira Albino ${ }^{2}$, Carla Rodrigues da Silva ${ }^{1}$, Horacio Santiago Rostagno², Paulo Cesar Gomes ${ }^{2}$, Camila Galdereto Borsatto ${ }^{3}$}

\author{
1 Pós-graduação em Nutrição de Monogástricos - UFV. \\ ${ }^{2}$ DZO/UFV \\ ${ }^{3}$ Graduando em Zootecnia - UFV.
}

RESUMO - O experimento foi conduzido com os objetivos de avaliar o efeito da suplementação de fitase em dietas sobre a energia metabolizável (EMAn) e sobre os coeficientes de digestibilidade ileal aparente de matéria seca, proteína bruta, cálcio e fósforo e determinar a deposição de cinzas, cálcio e fósforo na tíbia de frangos de corte. Foram utilizados 350 frangos de corte machos Ross de 16 a 25 dias de idade, distribuídos num delineamento inteiramente ao acaso, com cinco dietas e dez repetições de sete aves por unidade experimental. As dietas, à base de milho e de farelo de soja, foram formuladas considerando a disponibilidade de energia metabolizável, proteína bruta, lisina, cálcio e fósforo disponível, de acordo com a matriz nutricional da enzima fitase, e suplementadas com 0,5\% de oxido crômico. As dietas foram: controle positivo; controle negativo 1; controle negativo 2; controle negativo $1+250$ uft; controle negativo $2+500$ uft. A suplementação de enzima fitase nos níveis de 250 e de $500 \mathrm{uft} / \mathrm{kg}$ de dieta melhorou os valores energéticos das dietas, que aumentaram, em média, 36 e $54 \mathrm{kcal} / \mathrm{kg}$ de MS, respectivamente. A utilização de fitase melhorou os coeficientes de digestibilidade da proteína bruta e do fósforo, cujos maiores valores foram obtidos com a suplementação de 500 uft/kg de ração. A suplementação de fitase melhorou o coeficiente de digestibilidade e a retenção de fósforo, reduzindo o fósforo excretado, e aumentando a composição de fósforo na tíbia das aves, principalmente nos frangos de corte alimentados com a dieta suplementada com fitase (500 uft/kg). A suplementação de fitase (500 uft $/ \mathrm{kg}$ ) melhora o coeficiente de digestibilidade da proteína bruta e do fósforo, melhora a retenção de fósforo e diminui a excreção de fósforo de frangos de corte.

Palavras-chave: cálcio, digestibilidade, enzima, fósforo, tíbia

\section{Phytase dietetic supplementation on nutrients metabolism of broilers}

ABSTRACT - The experiment was carried out to evaluate the effect of phytase enzyme supplementation in diets on the metabolizable energy (ME) and on the apparent ileum digestibility coefficients of the dry matter, crude protein, calcium and phosphorous, and to determine the deposition of ashes, calcium and phosphorous on the tibia of broilers. It was used 350 Ross male broilers from 16 to 25 days of age distributed in a complete randomized design with five diets and ten replicates of seven birds per each experimental unit. The diets which were corn and soybean meal based were formulated considering the availability of metabolizable energy, crude protein, lysine, calcium, and available phosphorus according to the nutritional matrix of phytase enzyme, and supplemented with $0.5 \%$ of chromium oxide. The diets were the following: positive control; negative control 1; negative control 2; negative control $1+250$ ftu; negative control $2+500 \mathrm{ftu}$. The phytase enzyme supplementation at levels of 250 and $500 \mathrm{ftu} / \mathrm{kg}$ of diet improved the energetic values of the diets by 36 and $54 \mathrm{kcal} / \mathrm{kg}$ of dry matter, respectively. The use of phytase improved the digestibility coefficients of crude protein and phosphorus, whose highest values were obtained with supplementation of $500 \mathrm{ftu} / \mathrm{kg}$ of diet. The phytase supplementation improved coefficient of digestibility and phosphorous retention reducing excreted phosphorous and increasing composition of phosphorous in the tibia of the birds, mainly for the broilers fed diet supplemented with phytase $(500 \mathrm{ftu} / \mathrm{kg})$. The phytase supplementation $(500 \mathrm{ftu} / \mathrm{kg})$ improves the digestibility coefficients of crude protein and phosphorous, improves the retention of phosphorus and reduces phosphorus excretion of broilers.

Key Words: calcium, digestibility, enzyme, phosphorus, tight 


\section{Introdução}

O desempenho dos animais depende, em grande parte, da digestibilidade dos nutrientes contidos nas rações e do grau em que estes nutrientes podem ser absorvidos e utilizados posteriormente. Sabe-se que diferentes proporções de alguns nutrientes nas rações não são digeridas por aves e que existem diferentes fatores que podem interferir na digestibilidade, absorção e utilização de nutrientes (Huisman, 1991). A disponibilidade dos nutrientes em vegetais pode ser afetada por agentes naturais que formam compostos complexos (Sebastian et al., 1998). A maioria dos ingredientes vegetais usados nas rações de aves contém compostos que podem apresentar efeitos antinutricionais como taninos, fitato, polissacarídeos não-amiláceos, afetando o desempenho do animal. No entanto, uma proporção substancial destes é potencialmente suscetível à modificação enzimática (Acamovic, 2001).

Embora o uso de enzimas em rações não seja recente, sua aplicação de forma comercial na indústria avícola, como uma nova classe de aditivos, ocorreu no final da década de 1980 e seu uso bem-sucedido foi depois de 1992. No início da década de 1990, a aplicação de enzimas microbianas incluiu o uso de fitase, principalmente, em resposta à alta preocupação com a poluição do meio ambiente pelo fósforo das excretas dos animais; e após a comprovação da eficácia de várias fitases na degradação de diferentes proporções de fósforo-fitato nos ingredientes vegetais. Por isso, seu uso inicial limitou-se a países onde esta contaminação ambiental era penalizada. Baseados no fato que o fitato é um ânion reativo que pode formar uma ampla variedade de sais insolúveis com cátions bivalentes e trivalentes nutricionalmente importantes, além de formar complexos com proteínas e inibir a atividade de algumas enzimas digestivas (pepsina, tripsina e alfa-amilase), diversas pesquisas foram realizadas e mostraram sua eficácia para melhorar a digestibilidade de outros minerais, além de fósforo, proteínas e energia. Estes resultados, associados à proibição, em alguns países, do uso de ingredientes proteicos de origem animal, permitiram que esse uso fosse ampliado (Choct, 2006). A proibição da utilização de ingredientes proteicos de origem animal em rações possibilitou a expansão à outra área, a aplicação de enzimas em ingredientes proteicos de origem vegetal.

Trabalhando com frangos de corte na fase inicial de produção, Camden et al. (2001) concluíram que a adição de fitase em rações com níveis reduzidos de fósforo disponível e cálcio melhorou a retenção de nitrogênio e fósforo, reduzindo a excreção destes alimentos. Resultados semelhantes foram encontrados por Viveros et al. (2002), que observaram que a suplementação com fitase em rações com nível reduzido de fósforo disponível para frangos de corte, nesta mesma fase, aumentou a retenção de cálcio, fósforo, magnésio e zinco.

Desenvolveu-se este trabalho com o objetivo de avaliar o efeito da suplementação da enzima fitase em dietas sobre o metabolismo de nutrientes para frangos de corte.

\section{Material e Métodos}

Este experimento foi conduzido no período de 28 de maio a 6 de junho de 2006 utilizando-se 350 frangos de corte machos Ross de 16 a 24 dias idade, com peso médio inicial de $535 \mathrm{~g}$.

Até os 16 dias de idade as aves ficaram alojadas em um galpão de alvenaria, de piso coberto com maravalha, separadas de acordo com a dieta e recebendo, cada grupo, a dieta do respectivo tratamento.

Durante todo o período, adotou-se programa de luz contínua, com 24 horas de luz (natural + artificial) e aquecimento artificial dos pintos por meio de uma lâmpada de infravermelha de 250w/boxe e com altura regulável, ajustada para proporcionar o maior conforto possível às aves.

Aos 16 dias de idade as aves foram transferidas para baterias metálicas com $225 \mathrm{~cm}^{2}$ de área (45 cm de largura, $50 \mathrm{~cm}$ de comprimento e $40 \mathrm{~cm}$ de altura). Estas baterias foram equipadas com bandejas próprias para coleta das excretas.

As aves foram distribuídas num delineamento inteiramente ao acaso com cinco dietas e dez repetições de sete aves por unidade experimental.

A água e a ração foram fornecidas à vontade durante todo o período experimental, sendo os comedouros supridos de ração duas vezes ao dia, para evitar desperdício. Todas as rações foram formuladas à base de milho e farelo de soja. Foram adicionados $0,5 \%$ de oxido crômico a todas as dietas experimentais como indicador do fator de indigestibilidade.

As rações foram formuladas segundo as recomendações de Rostagno et al. (2005). A fitase utilizada foi a Fitase Quantum ${ }^{\circledR}$ (Syngenta Animal Nutrition). Para a formulação das dietas também foram considerados os aumentos na biodisponibilidade de energia metabolizável, proteína bruta, lisina digestível, cálcio e fósforo disponível obtidos com a suplementação da fitase, de acordo com a Tabela 1.

Dessa forma, os teores desses nutrientes foram reduzidos progressivamente nos controles negativos 1 e 2 e a essas dietas foram adicionados os níveis de fitase de 250 e $500 \mathrm{uft} / \mathrm{kg}$ da dieta, respectivamente. Assim foram 
constituídas as dietas: controle positivo; controle negativo 1; controle negativo 2; controle negativo $1+250$ uft; controle negativo $2+500$ uft (Tabela 2).

Os registros de temperatura interna do galpão foram obtidos com a instalação de dois termômetros de máxima e mínima, colocados em diferentes partes da instalação, à altura das aves. Os dados foram tomados duas vezes por dia (8 e 16 h).

Tabela 1 - Matriz nutricional da Fitase Quantum ${ }^{\circledR}$ de acordo com inclusão na dieta*

\begin{tabular}{lcc}
\hline & $\begin{array}{c}250 \text { uft/kg } \\
\text { de dieta } \\
\text { (nível 1) }\end{array}$ & $\begin{array}{c}500 \mathrm{uft} / \mathrm{kg} \\
\text { de dieta } \\
\text { (nível 2) }\end{array}$ \\
\hline Proteína bruta, \% & 0,12 & 0,36 \\
Cálcio, \% & 0,077 & 0,1 \\
Fósforo, \% & 0,1 & 0,13 \\
Energia metabolizável, kcal & 26 & 45 \\
Lisina digestível, \% & 0,003 & 0,010 \\
* Valores de acordo com o fabricante & &
\end{tabular}

Tabela 2 - Composição da ração experimental

\begin{tabular}{|c|c|c|c|}
\hline & $\begin{array}{l}\text { Controle } \\
\text { positivo }\end{array}$ & $\begin{array}{c}\text { Controle } \\
\text { negativo } 1\end{array}$ & $\begin{array}{c}\text { Controle } \\
\text { negativo } 2\end{array}$ \\
\hline \multicolumn{4}{|l|}{ Ingrediente (\%) } \\
\hline Milho & 56,362 & 58,195 & 59,691 \\
\hline Farelo de soja $45 \%$ & 36,853 & 36,256 & 35,459 \\
\hline Óleo de soja & 2,783 & 1,931 & 1,341 \\
\hline Fosfato bicálcico & 1,852 & 1,309 & 1,148 \\
\hline Calcário & 0,909 & 1,057 & 1,103 \\
\hline Sal & 0,502 & 0,502 & 0,501 \\
\hline DL-metionina $99 \%$ & 0,240 & 0,239 & 0,238 \\
\hline L-lisina $\mathrm{HCl}$ 79\% & 0,143 & 0,153 & 0,166 \\
\hline L-treonina $98 \%$ & 0,031 & 0,033 & 0,037 \\
\hline Mistura vitamínica 2 & 0,100 & 0,100 & 0,100 \\
\hline Mistura mineral $\underline{1}$ & 0,050 & 0,050 & 0,050 \\
\hline Cloreto de colina, $60 \%$ & 0,100 & 0,100 & 0,100 \\
\hline Anticoccidiano ${ }^{4}$ & 0,055 & 0,055 & 0,055 \\
\hline Antioxidante ${ }^{3}$ & 0,010 & 0,010 & 0,010 \\
\hline \multicolumn{4}{|l|}{ Nutriente } \\
\hline \multicolumn{3}{|l|}{ Energia metabolizável, } & 2.955 \\
\hline Proteína bruta, \% & 21,50 & 21,38 & 21,14 \\
\hline Cálcio, \% & 0,908 & 0,831 & 0,808 \\
\hline Fósforo disponível, \% & 0,454 & 0,354 & 0,324 \\
\hline Arginina digestível, \% & 1,382 & 1,370 & 1,349 \\
\hline Lisina digestível, \% & 1,170 & 1,167 & 1,160 \\
\hline \multicolumn{4}{|l|}{ Metionina + cistina } \\
\hline digestível, \% & 0,831 & 0,829 & 0,824 \\
\hline Metionina digestível, \% & 0,540 & 0,538 & 0,535 \\
\hline Treonina digestível, \% & 0,761 & 0,759 & 0,754 \\
\hline Triptofano digestível, \% & 0,242 & 0,238 & 0,234 \\
\hline \multicolumn{4}{|c|}{ 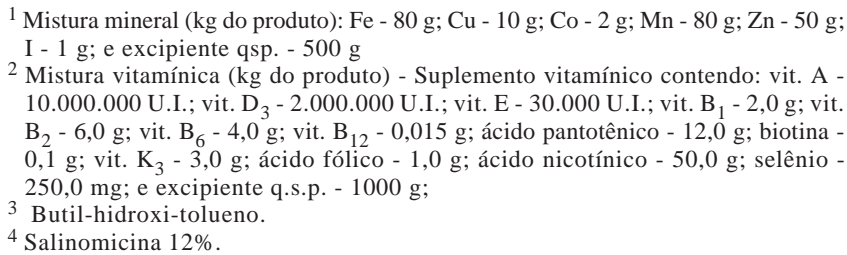 } \\
\hline
\end{tabular}

As médias de temperatura mínima e máxima foram de 19,8 e $23,7^{\circ} \mathrm{C}$, respectivamente.

A digestibilidade dos nutrientes, energia metabolizável aparente corrigida pela retenção de nitrogênio, os coeficientes de digestibilidade ileal aparente da matéria seca, da proteína bruta, do cálcio e do fósforo foram determinadas utilizando-se dois métodos: a coleta total de excretas e a digestibilidade ileal.

O período experimental foi de dez dias, sendo cinco para adaptação dos pintos às baterias e cinco para coleta de excretas. No período de 21 a 25 dias de idade se procedeu à coleta total de excreta para posteriormente determinar os valores de energia metabolizável das rações. As coletas de excretas foram feitas duas vezes ao dia com intervalos de 12 horas entre cada coleta. Para evitar contaminações e perda de amostra experimental, as bandejas foram revestidas com plástico e colocadas sob o piso de cada unidade experimental. As excretas coletadas foram colocadas em sacos plásticos, devidamente identificadas, pesadas e armazenadas em freezer até o final do período de coleta.

Aos 25 dias de idade, todas as aves de cada repetição foram abatidas por deslocamento cervical e imediatamente disseccionadas para obtenção da digesta do íleo terminal, desde o ponto de $5 \mathrm{~cm}$ antes da junção íleo-cecal até $40 \mathrm{~cm}$ em direção ao duodeno. Duas horas antes do abate, os frangos foram estimulados a consumir ração, para evitar que o segmento do íleo coletado apresentasse pouco conteúdo intestinal (Sakomura \& Rostagno, 2007). Este segmento de $40 \mathrm{~cm}$ foi seccionado transversalmente e seu conteúdo retirado e colocado dentro de copo plástico. Foram coletadas as tíbias de duas aves por repetição para posteriormente serem feitas as análises do conteúdo de cinzas, cálcio e fósforo.

As excretas coletadas foram acondicionadas em bandejas plásticas devidamente identificadas, pesadas e posteriormente homogeneizadas e retiradas alíquotas, que foram colocadas em estufa de circulação de ar à temperatura de $60^{\circ} \mathrm{C}$ para a pré-secagem. Posteriormente foram realizadas as análises de matéria seca, proteína bruta, energia bruta, fósforo, cálcio e cromo. Todas as análises foram realizadas em duplicatas no Laboratório de Nutrição Animal do Departamento de Zootecnia da UFV, pela metodologia descrita por Silva \& Queiroz (2002).

Ao término do experimento foi determinada a quantidade de ração consumida por unidade experimental, durante os cinco dias de coleta.

Uma vez obtidos os resultados de análises laboratoriais das rações, excretas e digestas, foram calculados os valores de energia metabolizável aparente corrigida pela retenção 
de nitrogênio (EMAn), os coeficientes de digestibilidade ileal aparente de matéria seca, proteína bruta, cálcio e fósforo, o fósforo retido em \% e em gramas por ave/dia e, finalmente, a deposição de cinzas, cálcio e fósforo na tíbia. Os coeficientes de digestibilidade e os valores de energia foram determinados com base nos níveis de cromo nas dietas e na digesta ou excreta, por meio do cálculo do fator de indigestibilidade.

Os coeficientes de digestibilidade e os valores de energia foram determinados com base nos níveis de cromo nas dietas e na digesta ou excreta, por meio do cálculo do fator de indigestibilidade.

Os resultados obtidos foram submetidos à análise de variância e à comparação de médias analisada pelo teste de Student-Newman-Keuls (SNK) a 5\% de significância, usando o programa estatístico SAEG (UFV, 2000).

\section{Resultados e Discussão}

Para os valores de energia metabolizável aparente corrigida pelo balanço de nitrogênio, as dietas que tiveram seus níveis nutricionais reduzidos foram inferiores $(\mathrm{P}<0,05)$ à dieta controle positivo, mas quando as dietas foram suplementadas com fitase, os valores foram semelhantes $(\mathrm{P}<0,05)$ à dieta controle positivo (Tabela 3$)$.

De maneira geral os valores de energia metabolizável determinados para as dietas controle positivo, controle negativo 1 e controle negativo 2 foram similares aos valores calculados. A suplementação de fitase nos níveis de 250 e 500 uft melhorou, em média, os valores energéticos das dietas em 36 e 54 kcal/kg de matéria seca, respectivamente.

Lan et al. (2002) ao avaliarem os valores de energia metabolizável de rações à base de milho e farelo de soja observaram que a adição da fitase microbiana nos níveis de 250 e 500 uft/kg em rações com baixo nível de fósforo proporcionou valores de energia metabolizável aparente superiores aos encontrados em uma ração com nível normal de fósforo e sem suplementação enzimática. Um incremento na utilização da energia metabolizável aparente corrigida pelo balanço de nitrogênio também foi observado por Farrel (1993).

Para os coeficientes de digestibilidade ileal da matéria seca e de cálcio, não foi observada diferença estatística $(\mathrm{P}>0,05)$ entre os tratamentos utilizados.

Não houve diferença $(\mathrm{P}>0,05)$ dos valores de coeficiente de digestibilidade de proteína bruta para a dieta controle positivo e as dietas com níveis nutricionais reduzidos. O mesmo foi observado quando se comparou os valores obtidos para a dieta controle negativo $1 \mathrm{com}$ a dieta suplementada com 250 uft de fitase. Quando se comparou a dieta controle negativo $2 \mathrm{com}$ a dieta suplementada com fitase (500 uft), observou-se melhora na digestibilidade da proteína bruta $(\mathrm{P}<0,05)$, sendo o aumento da digestibilidade de $2,47 \%$.

Os valores de coeficiente digestibilidade ileal de fósforo foram inferiores $(\mathrm{P}<0,05)$ para as dietas que tiveram os níveis nutricionais reduzidos em relação ao controle positivo. A dieta com suplementação de fitase (250 uft) melhorou em $8,97 \%$ o coeficiente de digestibilidade do fósforo, quando comparado à dieta controle negativo $1 \mathrm{e}$ foi estatisticamente semelhante ao controle positivo. A dieta com suplementação de fitase (500 uft) melhorou em 29,47\% o coeficiente de digestibilidade do fósforo, quando comparado à dieta controle negativo $2 \mathrm{e}$ foi superior $(\mathrm{P}<0,05)$ ao controle positivo em 12,79\%.

Estes resultados discordam em parte daqueles observados por Konergay (1996) e Sebastian et al. (1997), que verificaram em seus estudos melhorias na digestibilidade de proteína e de aminoácidos, com a adição de fitase microbiana em 1,8 a 4,3\%, respectivamente. De acordo com

Tabela 3 - Energia metabolizável aparente corrigida pelo balanço de nitrogênio e coeficiente digestibilidade ileal de nutrientes em frangos de corte alimentados com rações suplementadas com fitase ${ }^{1}$

\begin{tabular}{|c|c|c|c|c|c|c|c|}
\hline & $\begin{array}{l}\text { Controle } \\
\text { positivo }\end{array}$ & $\begin{array}{c}\text { Controle } \\
\text { negativo } 1\end{array}$ & $\begin{array}{l}\text { Controle } \\
\text { negativo } 2\end{array}$ & $\begin{array}{c}\text { Controle } \\
\text { negativo } \\
1+250 \\
\text { uft }\end{array}$ & $\begin{array}{c}\text { Controle } \\
\text { negativo } \\
2+500 \\
\text { uft }\end{array}$ & $\mathrm{CV} \%$ & Anova \\
\hline \multicolumn{8}{|c|}{ Energia metabolizável aparente corrigida pelo balanço de nitrogênio } \\
\hline Calculada & 3.436 & 3.410 & 3.393 & 3.436 & 3436 & & \\
\hline Determinada & $3.355 a$ & $3.282 b$ & $3.269 b$ & $3.318 \mathrm{ab}$ & $3.323 \mathrm{ab}$ & 1,52 & $\mathrm{P}<0,003$ \\
\hline \multicolumn{8}{|c|}{ Coeficiente de digestibilidade ileal } \\
\hline Matéria seca, \% & 76,58 & 76,81 & 76,04 & 75,64 & 76,13 & 2,49 & ns \\
\hline Proteína bruta, \% & $83,44 a b$ & $82,94 b$ & $82,94 b$ & $84,13 a b$ & $84,99 a$ & 1,78 & $\mathrm{P}<0,006$ \\
\hline Fósforo, \% & $53,79 b$ & $47,62 \mathrm{c}$ & $46,86 \mathrm{c}$ & $51,89 b$ & $60,67 a$ & 6,26 & $\mathrm{P}<0,001$ \\
\hline Cálcio, \% & 51,64 & 49,58 & 49,58 & 49,79 & 51,46 & 8,03 & ns \\
\hline
\end{tabular}

${ }^{1}$ Médias seguidas por letras distintas na mesma linha diferem $(\mathrm{P}<0,05)$ entre si pelo teste $\mathrm{SNK}$. 
os autores, o fitato presente nos alimentos inibe a ação de enzimas digestivas e, ao adicionar a fitase para quebrar o complexo do fósforo fítico, diminui-se a ação do fitato sobre estas enzimas aumentando a digestibilidade.

Utilizando dois níveis de suplementação de fitase, 500 e $750 \mathrm{ftuft} / \mathrm{kg}$ de dieta, Tejedor et al. (2001) comprovaram que a adição de ambos os níveis incrementou os coeficientes de digestibilidade de proteína bruta em 1 e 1,7\%; de energia bruta em 1 e 1,2\%; de cálcio em 3,5 e $5 \%$; e de fósforo em 3,5 e $4 \%$, respectivamente, para os níveis de fitase 500 e $750 \mathrm{uft} / \mathrm{kg}$ de dieta.

Observando o parâmetro fósforo retido em $\mathrm{mg} / \mathrm{ave} / \mathrm{dia}$ e fósforo retido em termos percentuais, verificou-se que as dietas com menores valores de fósforo disponível foram também as que tiveram os menores valores de fósforo retido. A suplementação de fitase (250 uft) ao controle negativo 1 não foi suficiente para melhorar $(\mathrm{P}<0,05)$ os valores de fósforo retido (mg/ave/dia), mas melhorou a retenção do fósforo em 7,42\%, apresentando valores semelhantes ao controle positivo. Quando a dieta controle negativo 2 foi suplementada com fitase ( $500 \mathrm{uft}$ ), os valores de fósforo retido ( $\mathrm{mg} / \mathrm{ave} / \mathrm{dia}$ e \%) foram superiores $(\mathrm{P}<0,05)$ ao controle negativo 2 e ao controle positivo. A melhora da retenção do fósforo (mg/ave/dia e \%) foi de 43,93 e 49,65\%, respectivamente (Tabela 4).

Como consequência da maior retenção de fósforo, a dieta com suplementação de fitase (500 uft) apresentou menor quantidade de fósforo excretado (mg/ave/dia) $(\mathrm{P}<0,05)$. A redução da quantidade de fósforo excretado com a suplementação de fitase (500 uft) foi de 39,97\%, em relação à dieta controle negativo 2, e 51,35\%, em relação à dieta controle positivo. O controle positivo apresentou maiores valores de fósforo excretado, que pode ser explicado pela maior quantidade de fósforo contido na dieta.

Estes resultados concordam com aqueles obtidos por Dourado et al. (2006) que, avaliando o efeito da suplementação da fitase sobre a digestibilidade dos nutrientes em dietas para frangos de corte, encontraram maior retenção de fósforo pelas aves alimentadas com dietas suplementadas com a enzima fitase.

Não houve diferença significativa para a porcentagem de cinzas na tíbia das aves, exceto para a dieta controle negativo 2 , que foi inferior $(\mathrm{P}<0,05)$ ao controle positivo (Tabela 5). A composição de fósforo (\%) na tíbia foi influenciada quando o nível de fósforo da dieta sofreu maior redução, mas com a suplementação de fitase (500 uft), os valores foram semelhantes $(\mathrm{P}<0,05)$ ao controle positivo, sendo o aumento na deposição de $9,01 \%$.

Os resultados para deposição de cálcio (\%) na tíbia apresentaram-se semelhantes à deposição observada para o fósforo (\%), apresentando resultados inferiores quando os níveis nutricionais da dieta foram reduzidos. Quando as dietas foram suplementadas com fitase (500 uft), a deposição de cálcio (\%) na tíbia foi aumentada em 14,6\% quando

Tabela 4 - Balanço de fósforo em frangos de corte alimentados com rações suplementadas com fitase ${ }^{1}$

\begin{tabular}{|c|c|c|c|c|c|c|c|}
\hline & $\begin{array}{l}\text { Controle } \\
\text { positivo }\end{array}$ & $\begin{array}{c}\text { Controle } \\
\text { negativo } 1\end{array}$ & $\begin{array}{l}\text { Controle } \\
\text { negativo } 2\end{array}$ & $\begin{array}{c}\text { Controle } \\
\text { negativo } \\
1+250 \\
\text { uft }\end{array}$ & $\begin{array}{c}\text { Controle } \\
\text { negativo } \\
2+500 \\
\text { uft }\end{array}$ & $\mathrm{CV} \%$ & Anova \\
\hline Fósforo ingerido (mg/ave/dia) & 569,6 & 484,3 & 463,4 & 486,6 & 463,5 & & \\
\hline Fósforo excretado (mg/ave/dia) & $293,29 c$ & $263,38 b$ & $237,73 b$ & $247,85 b$ & $142,69 a$ & 10,78 & $\mathrm{P}<0,001$ \\
\hline Fósforo retido (mg/ave/dia) & $276,30 \mathrm{~b}$ & $220,87 b$ & $216,67 c$ & $238,77 c$ & $311,87 a$ & 10,75 & $\mathrm{P}<0,001$ \\
\hline Fósforo retido (\%) & $49,61 b$ & $46,22 \mathrm{c}$ & $46,22 \mathrm{c}$ & $49,65 b$ & $69,17 \mathrm{a}$ & 5,35 & $\mathrm{P}<0,001$ \\
\hline
\end{tabular}

${ }^{1}$ Médias seguidas por letras distintas na mesma linha diferem $(\mathrm{P}<0,05)$ entre si pelo teste SNK.

Tabela 5 - Deposição de cálcio e fósforo na tíbia de frangos de corte no período de 1 a 25 dias de idade alimentados com rações suplementadas com fitase

\begin{tabular}{|c|c|c|c|c|c|c|c|}
\hline & $\begin{array}{l}\text { Controle } \\
\text { positivo }\end{array}$ & $\begin{array}{c}\text { Controle } \\
\text { negativo } 1\end{array}$ & $\begin{array}{l}\text { Controle } \\
\text { negativo } 2\end{array}$ & $\begin{array}{c}\text { Controle } \\
\text { negativo } \\
1+250 \\
\text { uft }\end{array}$ & $\begin{array}{c}\text { Controle } \\
\text { negativo } \\
2+500 \\
\text { uft }\end{array}$ & $\mathrm{CV} \%$ & Anova \\
\hline Cinza (\%) & $39,85 a$ & $38,35 a b$ & $38,03 b$ & $39,15 a b$ & 39,43ab & 3,12 & $\mathrm{P}<0,009$ \\
\hline Fósforo (\%) & 6,91a & $6,59 \mathrm{ab}$ & 6,32b & $6,72 \mathrm{a}$ & 6,89a & 4,88 & $\mathrm{P}<0,001$ \\
\hline Cálcio (\%) & $16,40 \mathrm{ab}$ & 15,52 bc & $14,80 \mathrm{c}$ & $15,66 \mathrm{bc}$ & $16,96 a$ & 6,03 & $\mathrm{P}<0,001$ \\
\hline Fósforo (g) & $0,173 \mathrm{ab}$ & $0,172 \mathrm{ab}$ & $0,163 b$ & $0,180 \mathrm{ab}$ & $0,190 \mathrm{a}$ & 11,23 & $\mathrm{P}<0,049$ \\
\hline Cálcio (g) & $0,422 b$ & $0,405 b$ & $0,382 b$ & $0,420 \mathrm{~b}$ & $0,480 \mathrm{a}$ & 10,83 & $\mathrm{P}<0,001$ \\
\hline Relação cálco/fósforo & 2,47 & 2,36 & 2,34 & 2,33 & 2,52 & 8,45 & ns \\
\hline
\end{tabular}

Médias seguidas por letras distintas na mesma linha diferem $(\mathrm{P}<0,05)$ entre si pelo teste SNK. 
comparado ao controle negativo 2, e mostrou-se semelhante $(\mathrm{P}<0,05)$ ao controle positivo.

Quando foi analisada a deposição de fósforo na tíbia em gramas, somente a dieta com menores níveis nutricionais foi inferior $(\mathrm{P}<0,05)$ à dieta com suplementação de fitase (500 uft). Resultado que não foi acompanhado para a deposição de cálcio em gramas na tíbia, sendo a dieta suplementada com fitase (T5) superior às demais. Para a relação cálcio/fósforo calculadas de acordo com a deposição dos minerais, não houve diferença estatística.

Santos et al. (2005), trabalhando com diferentes níveis nutricionais de dietas (com e sem adição de fitase) e um controle positivo, demonstraram que as dietas que tiveram seus níveis nutricionais reduzidos apresentaram redução nos teores de cinzas, fósforo e cálcio dos ossos. Entretanto, a suplementação com fitase melhorou significativamente essas variáveis, que foram semelhantes às do controle positivo.

Yan et al. (2003) também verificaram, para frangos de corte na fase de 42 a 63 dias de idade, que níveis reduzidos de fósforo disponível afetam a deposição de cinzas nos ossos. Entretanto, com a utilização de fitase nas dietas, foi possível evitar diferenças entre os tratamentos. Evidenciando a eficiência desta enzima em hidrolisar o complexo ácido fítico - mineral, deixando-os livres para absorção e contribuindo para a mineralização dos ossos.

Resultados contraditórios foram encontrados por Laurentiz et al. (2005), trabalhando com composição da tíbia de frangos de corte alimentados com dietas contendo fitase e níveis reduzidos de fósforo. Observaram redução na porcentagem de cinzas e no teor de fósforo nas tíbias quando as aves foram alimentadas com dieta contendo níveis reduzidos de fósforo disponível; e mesmo com a inclusão de fitase nos níveis mais baixos de fósforo disponível não foi possível aumentar a deposição de cinzas nos ossos.

\section{Conclusões}

A utilização de fitase melhora os coeficientes de digestibilidade ileal da proteína bruta e do fósforo, no nível de 500 uft/kg de ração, e também o fósforo retido (mg/ave/ dia e \%), reduzindo o fósforo excretado e aumentando a participação de fósforo na tíbia de frangos de corte.

\section{Referências}

ACAMOVIC, T. Commercial application of enzyme technology for poultry production. World's Poultry Science Journal, v.57, p.225-242, 2001.
CAMDEN, B.J.; MOREL, P.C.H.; THOMAS, D.V. et al. Effectiveness of exogenous microbial phytase in improving the bioavailabilities of phosphorus and other nutrients in maize-soya-bean meal diets for broilers. Animal Science, v.73, n.2, p.289-297, 2001.

CHOCT, M. Enzymes for the feed industry: past, present and future. World's Poultry Science Journal, v.62, p.5-15, 2006.

DOURADO, L.R.B.; SAKOMURA, N.K.; FUKAYAMA, E.H. et al. Efeito da suplementação da fitase na digestibilidade dos nutrientes em rações de frangos de corte. Revista Brasileira de Ciência Avícola. Premio Lamas 2006, Supl. 8, p.12, 2006.

FARREL, D.J. The beneficial effects of a microbial phytase in diets of broilers chickens and duck-lings. Journal Physiology Animal Nutrition, v.69, p.278-283. 1993.

HUISMAN, J. Anti-nutritional factors in poultry feed and their management. In: EUROPEAN SYMPOSIUM POULTRY NUTRITION, 8., 1991, Venezian Meske, Italy. Proceedings... Venezian Meske, 1991. p.35-52.

KORNEGAY, E.T. Nutrient management of food animals to enhance and protect the environment. Danvers: CRC Press LLC, 1996. p.279.

LAN, G.Q.; ABDULLAH, N.; JALALUDIN, S. Efficacy of supplementation of a phytase-producing bacterial culture on the performance and nutrient use of broiler chickens fed corn-soybean meal diets. Poultry Science, v.81, n.10, p.1522-1532, 2002.

LAURENTIZ, A.C.; JUNQUEIRA, O.M.; MARQUES, R.H. et al. Composição do fígado e da tíbia de frangos de corte alimentados com dietas contendo fitase e níveis reduzidos de fósforo. Revista Brasileira de Ciência Avícola, Premio Lamas 2005, Supl. 7, p.92, 2005.

ROSTAGNO, H.S.; ALBINO, L.F.T.; DONZELE, J.L. et al. Tabelas brasileiras para suínos e aves: composição de alimentos e exigências nutricionais. 2.ed. Viçosa, MG: Universidade Federal de Viçosa, 2005. 186p.

SAKOMURA, N.K.; ROSTAGNO, H.S. Métodos de pesquisa em nutrição de monogástricos. Jaboticabal: Funep, 283p. 2007.

SANTOS, F.R.; SAKOMURA, N.K.; MENDONÇA, M.O. et al. Efeito da suplementação com fitase em dietas de frangos de corte sobre a viabilidade econômica e desempenho. Revista Brasileira de Ciência Avícola, Premio Lamas 2005, Supl. 7, p.119, 2005.

SEBASTIAN, S.; TOUCHBURN, S.P.; CHAVEZ, E.R. Apparent digestibility of protein and amino acids in broiler chickens fed a corn-soybean diet supplemented with microbial phytase. Poultry Science, v.76, p.1760-1769, 1997.

SEBASTIAN, S.; TOUCHBURN, S.P.; CHAVES, E.R. Implications of phytic acid and supplemental microbial phytase in poultry nutrition: A review. World's Poultry Science Journal, v.54, p.27-47, 1998.

SILVA, D.J.; QUEIROZ, A.C. Análise de alimentos: métodos químicos e biológicos. 3.ed. Viçosa, MG: UFV, 2002. 235p.

TEJEDOR, A.A.; ALBINO, L.F.T.; ROSTAGNO, H.S. et al. Efeito da adição da enzima fitase sobre o desempenho e a digestibilidade ileal de nutrientes. Revista Brasileira Zootecnia, v.30, n.3, p.802-808, 2001.

UNIVERSIDADE FEDERAL DE VIÇOSA - UFV. SAEG - Sistema de análises estatísticas e genéticas. Versão 8.0. Viçosa, MG: 2000. 59p. (Manual do usuário).

VIVEROS, A.; BRENES, A.; ARIJA, I. et al. Effects of microbial phytase supplementation on mineral utilization and serum enzyme activities in broiler chicks fed different levels of phosphorus. Poultry Science, v.81, n.8, p.1172-1183, 2002.

YAN, F.; KERSEY, J.H.; FRITTS, C.A. et al. Phosphorus requirements of broiler chicks six to nine weeks of age as influenced by phytase supplementation. Poultry Science, v.82, p.294-300, 2003. 